\title{
Urgences
}

\section{Textes volatiles (extraits)}

\section{Alain St-Yves}

Numéro 1, 2e trimestre 1981

URI : https://id.erudit.org/iderudit/025009ar

DOI : https://doi.org/10.7202/025009ar

Aller au sommaire du numéro

Éditeur(s)

Urgences

ISSN

0226-9554 (imprimé)

1927-3924 (numérique)

Découvrir la revue

Citer ce document

St-Yves, A. (1981). Textes volatiles (extraits). Urgences, (1), 47-54.

https://doi.org/10.7202/025009ar

Ce document est protégé par la loi sur le droit d'auteur. L'utilisation des services d'Érudit (y compris la reproduction) est assujettie à sa politique d'utilisation que vous pouvez consulter en ligne.

https://apropos.erudit.org/fr/usagers/politique-dutilisation/
Cet article est diffusé et préservé par Érudit.

Érudit est un consortium interuniversitaire sans but lucratif composé de l’Université de Montréal, l'Université Laval et l'Université du Québec à Montréal. Il a pour mission la promotion et la valorisation de la recherche. https://www.erudit.org/fr/ 


\section{ALAIN ST-YVES}

\section{Textes volatiles}

(extraits)
à Diane
à Pierre 
Tont le monde croira que ces textes

écrits à la hâte sur des feuilles ordinaires

sorties droit d'un cartable d'écolier

sont des écritures banales

et bien moi je vous le dis

je vous passe le secret

ces textes sont des poèmes subliminaux

Dans mon grand livre des tristesses il y aura toujours une page blanche pour toi

L'espoir est une chandelle allumée et son feu porte à lui seul toute la lumière des coeurs

Tes lèvres étaient de sable

C'est si compliqué de défaire brique par brique le mur qui nous cache la lumière

Nous nous demandions mon ami Clavet et moi pourquoi la politique était si souvent merdeuse ben c'est pas compliqué comme dit Jean-Claude elle est pleine d'hommes droits de rect'hommes 
Je me sens mal

j'ai le nez bouché

Les volets du coeur

peuvent se fermer pour un temps

ou pour toujours

et la maison se délabre

elle pleure dans le paysage

ses tristesses infinies

Plus tard

ceux qui passeront

voyant ces ruines envahies de fantômes

et de verdure

diront Ce devait être

une belle maison

Serais-je un jour

assez libre de toi

pour pouvoir te retrouver

Des fois je me sens appuyé au vide

et pourtant je tiens quand même debout

un peu croche mais ça va

je me sens comme une quenouille

dans l'épaule du vent

je reste ainsi parfois longtemps

je semble regarder quelque chose

mais mes yeux sont en dedans

profondément 
Fumisterie

Pour une justice infiniment haute et claire

faire sécher des feuilles d'Avocat

puis émietter

Rouler avec un papier à la vogue

et... fumer

Il y avait dans l'air

ton parfum

et cela me suffisait

Où irais-je pleurer comme un saule d'enfance

M. Samuel 73 ans

quand il parle de sa femme

il dit: Elle est comme une pomme

et ses yeux deviennent gourmands

Même les mots ont de la barbe

L'avion volait à main armée

et faisait des détournements

L'ire d'Iran l'ire d'Irak

On dirat une rengaine folklorique pour faire taper des pieds

mais là-bas

on se tape sur la tête

Lirediran liredirak et tigidon right true 
Je t’ai téléphoné mais j'avais rien à dire j"étais vidé vide comme une bouteille vide qu'on jette à la mer avec dedans juste un petit mot griffoné à la hâte a $u$ s e c c o ll $r$ s :

Je te serre tant que je veux dans mes bras ceux-ci étant le vent

J'aimerais $m$ 'asseoir dans ma berceuse avec toute la terre dans mon ventre et me bercer et me bercer me laisser chavirer

Parle au vent

il ne te trahira pas

On ne peut oublier on ne peut oublier on reste désemparé. un long moment puis on repart avec la tête lourde de pierres tombales et nos traits sont encore plus des flenves taris 
Le sourire est une tristesse parfois

On reste seul seul pour continuer les labours dans la mince espérance seul avec des pas qui s'obstinent à se souvenir seul à souquer l'amour désenvahi

Parfois

on a du gris dans le geste

Voici mon nombril

fourrez-vous le dans l'cul

il sera si près

ô si près de sa première chute

J'écris au rythme des courtepointes

Il y a des regards qui ne s'oublient pas

qui nous traversent la chair pour aller se semer

en nos frissons

en nos désirs printaniers d'avant le printemps

et tes regards étaient de ceux-là Mademoiselle

et c'était plus que de la lumière bleue aux fines étincelles

plus qu'un grand feu de plage

ce n'était pas de l'amour

mais c'était de l'amour de toute façon

comme un murmure

Il ne manquait que du vent sous ta robe diăphane et fleurie de collines

que du vent et qu'un peu de temps

Voici mon message sussuré du premier février Minouchez-vous les uns les autres... 
Je voudrais écrire la vie telle qu'elle est vous décrire le monde blessé de ses propres mains qui ne servent plus la semence je voudrais vous parler à voix haute des désastres qui free-jazzent la terre plâtrée et replâtrée

des guerres sortant des chapeaux noirs de quelques sorciers comme autant de lapins qui sautent et qui boumment je voudrais vous parler de la riche justice qui se gagne à la bourse je voudrais écrire juste la vérité démaquiller la politique et la religion jusqu'à l'os des normes et des mensonges ô nous déculpabiliser de ne pas toujours prendre parti et de rester méfiant je voudrais enfin éclater de tant de révoltes et de lumière mais je reste pris à mon crayon qui sanglote comme un petit enfant dans la nuit

Les étoiles sont vertes parce qu'elles ont poussé comme de l'herbe dans cette page blanche comme un lièvre d'hiver

Comment parlerais-je de moi sans mettre mon nombril au bout d'une ficelle comme un pendule pour trouver le milieu de moi et le riche équilibre

comment me tire-bouchonner pour me vider un brin

Les regards bleus sont des yeux d'îles et de ciel les regards bruns des yeux de bonne terre fraîche les regards verts sont des forêts qui se multiplient les gris ne sont pas nuageux comme vous le pourriez croire ce sont des yeux de laine chaude 
Je te parlerai de mes insécurités tu me parleras de tes insécurités et nous nous sécuriserons

L'écriveux n'avait rien écrit de la journée le soir venu devant sa feuille blanche qui attendait le souffle juste avant d'aller se coucher il écrivit: Je t'aime!!! ceci fait il se coucha en se disant à lui-mềme quelle belle journée d'écriture il venait de vivre là

Je voudrais que mes angoisses soient comme des oiseaux migrateurs qu'elles s'envolent vers le sud me laissant seul au nord déboussolé

Il y a un homme qui s'appelle Julos il y a un poète qui s'appelle Julos il $\mathrm{y}$ a des enfants qui ont un peu sa tête il y a un village quelque part qui s'appelle Julos et un lac aussi qui s'appelle Julos il y a des esprits qui s'appellent Julos dans la transparence il doit sûrement y avoir dans les galaxies une planète appelée Julos ou appelée à l'être bientôt 